\title{
THE INTERNATIONAL WOOL TEXTILE RESEARCH CONFERENCE, AUSTRALIA, 1955
}

$\mathrm{W}$ OOL is a most versatile fibre, and many facets of interest to scientists and those concerned with its growth and processing were examined at the Wool Textile Research Conference, held successively at Sydney, Goelong and Melbourne, under the chairmanship of Dr. F. W. G. White, during August 22-September 9 . The Conference was promoted, with much foresight and imagination, by the Commonwealth Scientific and Industrial Research Organization (C.S.I.R.O.) to mark the expansion of research into the wool textile field in Australia. Never before had so many wool scientists and technologists assembled together from many countries of the world. The excellent planning and organization of the many sessions held for the presentation and discussion of papers (some 140 or so in number) cnsured the success of the Conference, despite the wide range of scientific investigations that the Conference encompassed.

Many of the fifty-three overseas delegates, from Great Britain, the United States, France, Sweden, Germany, Japan, India, South Africa, Canada and New Zealand, attended by invitation of the Australian Government, and all would wish to express their appreciation of the hospitality received from both organizations and private individuals during this memorable occasion.

In addition to the scientific sessions, tours of the Sydney-Geelong region were organized so that delegates could learn at first hand of wool-growing, pastoral improvement, and irrigation in Australia.

Wool research under the Commonwealth Scientific and Industrial Research Organization has rapidly expanded in recent years, chemistry and biochemistry being directed by Dr. F. G. Lennox at Melbourne, physics and engineering by Dr. Burgmann at Sydney and technical development by Dr. M. Lipson at Geelong; reference should also be made to the McMaster Animal Health Laboratory at Glebe, Sydney, the Sheep Biology Laboratory at Prospect, the Animal Health Research Laboratory at Parkville, and other stations of the Organization and university departments. Some hundred delegates attended from these institutes. The overseas visitors were able to see the work in progress, which included amino-acid and peptide analysis, the study of crimp and other physical properties of fibres, and a new approach to solvent-scouring of wool. Australian workers contributed more than fifty papers, while those from abroad included twenty from the Wool Industries Researeh Association of Torridon, Leeds, eighteen from the University of Leeds, nine from other delegates from Britain, thirteen from the United States, and twenty-three from other countries.

Sevoral loctures, some to the delegates and scientific observers from universities and research centres and others open to the general public, were given during the Conference period. The public lectures each attracted an audience of five to six hundred, and this, together with other evidence, clearly indicated the public recognition of the contribution of the Commonwealth Scientific and Industrial Research Organization to the service of the community. The inaugural lecture at the Conference was given by Prof. W. T. Astbury, of the University of Leeds, who, in his own inimitable style, showed how early work on the structure of keratin fibres and materials had stimulated much of present-day thought and research on proteins. Dr. E. G. Carter, of the International Wool Secretariat, gave an excellent account of the part played by science in the study and use of wool to a large public audience at the University of Melbourne. Perhaps the most stimulating lectures, however, were those given by Prof. Robert B. Corey, Dr. F. Sanger and Prof. Emil L. Smith. Many of the overseas delegates had previously beard lectures from these investigators, but it is certain that even these delegates were again thrilled to hear a first-hand account of the masterly researches of Corey and Pauling on the configuration of the proteins, of Sanger on the structure of insulin, and of Smith on structure determinations of papain. Every one present appreciated the significance of Sanger's statement that the molecular weight of insulin is 5733.

In addition to these Conference lectures, many delegates addressed local societies and other groups interested in scientific and technical advances in the use of wool. There was, in fact, a wide exchange of opinions and information and there is little doubt that many opportunities were taken to co-ordinate research between different countries.

It is impossible within reasonable space to give a detailed account of all the papers presented at the Conference; but a useful purpose will be served by giving, for each of the main sciences, the outstanding features, with special reference to new work, that were made available either by a single paper or by a group of contributions. Some idea of the amount of material made available to the Conference will be gained by the anticipated size of the Conference Proceedings, to be published in the near future, namely, more than 2,000 pages that will occupy five or six volumes.

\section{Chemistry}

In the chemical studies, the emphasis was understandably on proteins. Dr. F. Sanger (University of Cambridge), in addition to describing the investigations carried out by his team of research workers on the distribution of the cystine residues in insulin, with special reference to the cyclic structure formed by intramolecular dithio linking, discussed cysteic acid peptides formed by oxidation and subsequent partial hydrolysis of wool ; paper ionophoresis under high voltage indicates a very complex mixture in whioh serine- and glutamic acid-cysteic acid peptides predominate. Researches on the enzyme papain, parallel in many ways with those of Sanger and eo-workers on insulin, were reported by Prof. Emil Smith. The crystalline protein and also its mercuric derivative have been studied and much of the aminoacid sequence has been elucidated. One interesting feature of this work is that, of the eight sulphur atoms present in the molecule, only six can be accounted for as cystine or cysteine and, in this connexion, it should be noted that in wool only 85-86 per cent of the total sulphur appears to be present as cystine-sulphur, due, according to Dr. 
D. H. Simmonds (C.S.I.R.O. Wool Textile Research Laboratory, Melbourne), to the presence of 14-15 per cent of elementary sulphur. This latter finding was reported in a paper by Simmonds in which were given complete amino-acid analyses for four samples of wool fibre.

The availability of a complete amino-acid analysis for wool would mark the end of the first stage in the study of the keratin molecule. Unfortunately, there are several problems to be resolved with regard to the data available. Simmonds's data agree reasonably well with those of Dr. A. Robson and M. C. Corfield (Wool Industries Research Association, Leeds), which were also reported to the Conference; but there are differences in the values for certain of the amino-acids that appear to be outside the tolerance of accuracy of the analytical methods used. In addition, the content of some aminomacids clearly differs with different wools; this is undoubtedly true of cystine and tyrosine, and possibly occurs with phenylalanine, glycine, aspartic acid and threonine. The data available account for 96 per cent (Simmonds) to 99 per cent (Robson and Corfield) of the total nitrogen, and hence the unknown sulphur fraction must exist as elementary sulphura theory not readily acceptable to most protein chemists - or to the presence of a polysulphide group in place of the cystine-dithio linkage.

Many papers were concerned with the constitution of the keratin molecule. Dr. S. Blackburn and G. R. Lee (Wool Industries Research Association, Leeds) reported that the method of hydrazinolysis of Akabori et al. shows glycine, alanine, serine and threonine to be carboxyl terminal groups in intact wool. Most workers in this field, however, are concerned with the obvious heterogeneity of the wool fibre and have attempted to separate, either from the whole fibre or some histological fraction, for example, cortical cells, a soluble protein or protein degradation product. Experiments in this direction, carried out by means of thioglycollic acid, were described by Dr. F. G. Lennox and by J. M. Gillespie (both of the C.S.I.R.O. Wool Textile Research Laboratory, Melbourne), while Dr. P. Alexander and Dr. L. F. Smith (Chester Beatty Research Institute, London) claimed that oxidative fission, achieved by peracetic acid followed by extraction with aqueous ammonia, affords products of a lower degree of peptide-chain degradation. I. J. O'Donnell and E. F. Woods (C.S.I.R.O. Wool Textile Research Laboratory, Melbourne) reported a comparison between the reductive and oxidative methods, and Dr. B. S. Harrap (of the same Laboratory) examined some of these preparations for molecular weight by the spreading monolayer technique; for $\alpha$-keratose he obtains values ranging from 7,500 to 70,000 depending on the $p \mathrm{H}$ and ionic strength of the solvent. Prof. H. Zahn and J. Meienhofer (University of Heidelberg) obtained products, which they call wool gelatin, by extraction of wool with cold water; but there is some doubt as to the wool keratin being the direct source of their material. The bearing of the nature of soluble protein material from wool on the regeneration of wool fibres was discussed by Dr. F. Happey (Bradford Technical College).

Much attention was given to the reactivity of the disulphide bonds in proteins and peptides. Alkaline treatment of wool results in formation of lanthionine, and this reaction was discussed by Prof. A. Schöberl and Annemarie Wagner (Veterinary School, Hamburg), by Prof. H. Zahn, and by Dr. S. Blackburn and G. R. Lee (Wool Industries Research Association, Leeds); these workers described a method for the determination of lanthionine based on the spectral absorption of the ninhydrin colour, whereas Dr. E. O. P. Thompson (C.S.I.R.O. Wool Textile Research Laboratory, Melbourne) resorted to bromine oxidation. The separation of the diastereoisomerides of lanthionine was described by Schöberl and Wagner and by Blackburn and Lee. The mechanism of the formation of lanthionine and the preparation and properties of derivatives of lanthionine were given in papers by Zahn and by Dr. J. M. Swan and co-workers (C.S.I.R.O. Wool Textile Research Laboratory, Melbourne).

The attention that has been given to the extraction products of high molecular weight and to the products of partial hydrolysis was reflected in the papers devoted to their separation. Thus Dr. R. L. M. Synge (Rowett Research Institute, Aberdeen) discussed the separation of larger peptides and advanced considerations that merit serious study, while the paper by Dr. A. J. P. Martin (National Institute for Medical Research, London) on the partition chromatography of proteins was a valuable contribution to this subject; in this connexion, Dr. Sanger recommended the use of paper ionophoresis at high voltages for use with peptides.

A fuller utilization of wool has been developed by chemical treatment of the fibre; this was shown by papers on this subject, especially those by Prof. J. B. Speakman and his co-workers of the University of Leeds, who gave a series of papers describing investigations on the chemical mechanism of permanent set, on cross-linking by the use of formaldehyde and of ninhydrin, and on the setting of stained fibres at low temperatures. Prof. Zahn, in a lecture to the Conference, described the use of mono- and bi-functional cross-linking.agents and their effect on the resistance of the fibre to degradative processes, and a paper by J. E. Moore and Dr. H. P. Lundgren (U.S. Department of Agriculture) referred to dimaleimides as cross-linking agents. Prof. M. Oku and I. Shimizu (Kobe University, Japen) claimed that the stability and mechanical properties of wool are improved by formaldehyde cross-linking, achieved. by treatment with hexamethylenetetramine.

A new approach to the chemical modification of the wool fibre was shown by Wikström and coworkers (Swedish Textile Research Institute, Gothenburg), who found that the surface reactivity of the fibre could be increased by treatment with chemical reagents, especially hydroxyl ions and organic solvents ; it is of interest to note that W. G. Crewther (C.S.I.R.O. Wool Textile Research Laboratory, Melbourne) noted in his paper that hydroxyl ions increase the susceptibility of wool fibres to proteolytic attack. A paper of practical importance in the shrink-proofing of wool, given by R. Bentham, C. B. Stevens and Prof. C. S. Whewell (University of Leeds), dealt with the action of hypochlorites on wool that had been modified by treatment with alkalis, acids, deaminating agents and dyes. All these contributions place emphasis on the part played by the cuticular layers of the wool fibre in chemical processes.

The general trend of work on the chemical modification was well exemplified in a lecture by Dr. H. P. Lundgren, who discussed the stability of the hydrogen-bonded wool structure, as shown by the reaction with $\beta$-propiolactone, the stability of the disulphide bonds, the behaviour of wool on heating or exposing to ultra-violet light and the protection 
of wool against such agents by the uso of, for example, titanium alkoxides; one interesting observation in this lecture was that the yellowing of wool is promoted by suint, one active principle of which is urocanic acid (a glyoxaly]acrylic acid).

\section{Physics}

The application of reaction-rate theory of viscoplasticity to wool was the subject of a lecture by Prof. H. Eyring (University of Utah) and of one of the physics sessions. This theory often merely expresses the usual experimental results in an alternative form, but a stimulating paper by Dr. L. Peters (University of Leeds) attempted to relate the statistical parameters to a molecular model of the fibre. The interaction of wool and water again brought reaction-rates to the fore, and some beautiful experimental work from the C.S.I.R.O. Wool Textile Research Laboratory at Sydney provided data for the very rapid diffusion of water into single fibres. A paper by F. L. Warburton (Wool Industries Research Association, Leeds) showed how useful the wet-bulb theory could be for calculations of drying and conditioning on an industrial seale.

A review of the present position of research on worsted spinning was contributed by J. Ingham (Wool Industries Research Association, Leeds), and Dr. Margaret Hannah (University of Leeds) discussed problems of high-draft spinning. This session also considered woollen carding and spinning and the design of experiments when industrial plant has to be used. Fibre arrangement and the behaviour of fibres during mechanical processing were surveyed in a series of papers presented by British and Australian delegates. Wet processes, together with dyeing and finishing, were discussed in three sessions, the most interesting development being the solvent scouring system used at Geelong. Much information was also made available on the degradation of wool during wet processing, and the full report of the Conference should provide manufacturers with an excellent guide to precautions that are necessary when subjecting wool to acid or alkaline conditions. The sessions on manufacturing processes were concluded by a symposium at Geelong with some four hundred members of the local textile industry, where a lively discussion followed short addresses by Dr. A. B. D. Cassie, Dr. J. G. Martindale and Prof. C. S. Whewell.

\section{Histology}

The fine histology of wool and the recent discovery of its bilateral structure provided much material for exchange of experience and opinion. There seems little doubt that the bilateral structure contributes largely to the crimp of wool, and because of the different reactions of the two structures to swelling, it may well be a principal factor in maintaining the bulkiness, and therefore the warmth, of wool fabrics. Although much was discussed about the wool follicle and its blood supply, no suggestion was made as to how this difference in keratinization, apart from references to Auber's work on detailed segmental keratinization, or possibly even in chemical composition, might arise. The histology of the wool fibre and that of its follicle are subjects that require much more research, possibly with entirely new approaches. The fine structure of wool is slowly being revealed by the electron microscope, and infra-red absorption spectra coupled with deuteration of the protein chains not locked in crystallites offer opportunities for considerable advance in our knowledge of wool structure. It must be remembered, however, that although the crystallographers may solve the problem of the crystal structure of keratin, they will have thrown only a little light on how wool works. The contributions by Dr. R. D. B. Fraser (C.S.I.R.O. Wool Textile Research Laboratory, Melbourne) and by G. King (Wool Industries Research Association, Leeds) on the infra-red spectra of swollen fibres were, therefore, most welcome.

There were also sessions on wool as a textile fibre, where students of genetics and nutrition sought guidance from the physicists and chemists on the fibre characteristics desired by the wool manufac. turer. These discussions revealed again the uncertainty that exists concerning the uniformity of the physical and chemical properties of wool ; and until greater accuracy is attained in such measurements, the biologist can only seek greater regularity of length, diameter and crimp. Many of the difficulties facing the physicist and chemist in finding variations in the properties of wool are probably due to the heterogeneous samples that normally come their way, and one outcome of the Conference has been the establishment of contacts that will provide wool samples from flocks of a definite type of sheep, or even from different parts of one or more fleeces : in this connexion, a scheme has been proposed for the preparation of, for example, large samples of finely cut, clean wools so that workers all over the world may have a common source of material for amino. acid analysis, etc.

As a final note, it is appropriate to consider the Conference in its wider perspective, made possible by the numerous and long-distance tours that the delegates, either individuals or in parties, were able to make during their stay in Australia. Herc was a vast expanse of land, much of it scrub and with large tracts of uncultivatable soil. Yet to-day approximately 127 million Australian sheep are producing more than 1,200 million lb. of greasy wool, 74 per cent of which is merino. This is merely a reflexion of the strength and endeavour of the Australian people who, as described in the Conference Handbook, "live in a dynamic economy". Since the introduction at the end of the eighteenth century of the first merinos into Australia and Tasmania, the land has been cleared and the pasture improved in order to raise such an immense number of the descendants of the original small stock. The arduous task of developing the refractory land was first achieved by the early settler, but to-day the Australian Mutual Provident Society is organizing and financing land clearance on a large scale. Terrain capable of feeding one-half or less sheep per acre is improved to levels of two or more per acre. This improved pasturage has been mado possible by the work of the Commonwealth Scientific and Industrial Research Organization, which has investigated the vital questions of soil fertilization, selection of grasses, clovers, etc., the problems of metal deficiency in soils, and the many factors in the breeding and care of sheep.

Irrigation also presents a serious problem in a country where the rainfall is generally meagre and irregular. The delegates saw vast areas in Victoria and South Australia where there was serious flooding and where, in the summer months to come, the land 
will be dry and parched. Extensive schemes of irrigation and water conservation have been carried out or are nearing completion, and delegates had the opportunity of appreciating the magnitude of these schemes by visits to the Snowy Mountains and to dams under construction, such as that at Warragamba.

To-day there are stud farms where the merino stock is maintained, and the delegates were able to visit such studs near Deniliquin and those in the Macquarie Valley region in Tasmania, where a very pure strain of fine-woolled merinos is maintained. Research on genetics and growth of sheep by the Commonwealth Scientific and Industrial Research Organization has been most active. The occurrence of 'steely wool' and malnutrition of the sheep was traced to cobalt deficiency. The wide need for phosphate fertilization of the soil was demonstrated, and to-day problems such as 'staggers' due to Phalaris tuberosa are being investigated.

The people of Australia in general and the graziers in particular have come to appreciate the invaluable work of the Commonwealth Scientific and Industrial Research Organization, and the importance of the Conference to Australia was indicated by the presence of the Prime Minister and several colleagues at the inaugural dinner, and by the reception of all delegates by the Governor-General and Lady Slim at Canberra. A. B. D. CAsste

F. O. How TT

\section{SOIL MECHANICS, GEOLOGY AND CIVIL ENGINEERING}

$\mathrm{D}$ URING the recent meeting at Bristol of the British Association, a most informative joint meeting between Section C (Geology) and Section G (Engineering) took the form of a symposium to discuss the interdependence of geology, civil engineering and the new science of soil mechanics. Mr. F. H. Edmunds, of the Geological Survey of Great Britain, introduced the discussion. He pointed out that the civil engineer, in order to make an appreciation of the likely reactions of the rocks to his activities, requires as full geological information as possible concerning a new site, particularly in regard to the physical characteristics of rocks as determined from small samples (their hardness, cohesion, porosity of the rock) ; the arrangement of rock masses and strata at an engineering site (whether they lie horizontally or are inclined or buckled or folded, etc.) ; and the potentialities of water storage in, and movement through, the rocks. Detailed geological information is more necessary to-day than in former years for two main reasons: through advances in technique and machinery, many civil engineering works of to-day are immensely larger and more complex than those of past days; and whereas the old engineers usually had the choice of site, present-day works often have to be constructed at sites imposed on the engineer. These may be on alluvial tracts, in coastal areas, or in other difficult situations where the ground is occupied by thick beds of unconsolidated material, in many instances saturated with water.

Up to thirty years ago, geological science had more or less ignored petrological studies of soft sediments. The physical characteristics of soft rocks and, in the case of clays, differences of behaviour relative to the variable factor of the amount of adsorbed water in them, had received scant notice; but these points are of vital importance to engineers. In the circum. stances, engineers and physicists set out themselves to get information of the kind required. From their work has evolved the science of 'soil mechanics'.

The word 'soil' in this connexion connotes soft unconsolidated material irrespective of its thickness or of its depth below ground surface; it has but little connexion with the top several inches of the earth's crust associated with agriculture. Generally speaking, what the engineer calls 'soils' are the 'soft rocks' of geological terminology, for example, sand and clay. Their essential feature, however, is lack of consolidation.
Much of soil mechanics investigations is a matter of physics undertaken in the laboratory, but laboratory tests by themselves are incomplete. To obtain the fullest information from them the small samples used need to be related to the stratigraphy of the beds from which they are taken.

Mr. P. L. Capper, of University College, London, described the fundamentals of soil mechanics. Soilused in the engineering sense-necessarily forms, in its natural condition, the foundation for all works of construction, except where these can be founded directly upon solid rock. It is also used extensively as a constructional material, for example, in embankments, dams and earth roads. In designing any members of an engineering structure, four points have to be considered : the load or external forces applied to the member ; the internal forces and stresses set up in the member ; the deformations produced; and the way in which failure will take place if the member is overloaded. The same applies to soil ; but compared with other materials of construction, soil presents greater difficulties on account of its lack of uniformity and its susceptibility to changes in its properties arising from variation in the water content. Soil mechanics comprises three main divisions : mechanics of soils, that is, the loss of equilibrium induced by engineering work, stress distribution and movement of water in soil; site investigation and the testing of soil for the determination of the relevant properties; the application of the findings under the first two headings for civil engineering design and construction.

The first division of soil mechanics includes the study of the conditions of stability of masses of soil, the determination of the internal stresses set up in soil under the action of external and gravitational forces and study of the laws governing the movement of water in soil. As with other engineering materials, the solution of stability and stress-distribution problems in soil involves an application of statics combined with assumptions as to deformation characteristics such as elasticity or plasticity.

In deciding upon the depth to which an investigation should be carried out, the chief point is to estimate the depth of soil which will be appreciably affected by the applied loads, and this depends upon the extent of the loaded area. The concept of the bulb of pressure illustrates this principle. The most important soil properties from the engineer's point of 